\title{
A multicentre retrospective comparison of central nervous system prophylaxis strategies among patients with high-risk diffuse large B-cell lymphoma
}

C Y Cheah ${ }^{1,2}, \mathrm{~K}$ E Herbert ${ }^{1,2,3}, \mathrm{~K}^{\prime} \mathrm{O}^{\prime}$ Rourke $^{4}$, G A Kennedy ${ }^{4,5}$, A George ${ }^{1}$, P L Fedele ${ }^{6}, \mathrm{M} \mathrm{Gilbertson}^{6,7}$, S Y Tan ${ }^{6}$, D S Ritchie ${ }^{1,2}$, S S Opat ${ }^{6,7}$, H M Prince ${ }^{1,2,3,7}$, M Dickinson ${ }^{1,2}, K_{\text {Burbury }}^{1,2}$, M Wolf ${ }^{1,2,3}$, E H Januszewicz ${ }^{1}$, C S Tam ${ }^{1,2}$, D A Westerman ${ }^{1,2}$, D A Carney ${ }^{1,2}$, S J Harrison ${ }^{1,2}$ and J F Seymour ${ }^{\star, 1,2}$

${ }^{1}$ Department of Haematology, Peter MacCallum Cancer Centre, Locked Bag 1, A'Beckett Street, Melbourne, Victoria 8006, Australia; ${ }^{2}$ Sir Peter MacCallum Department of Oncology, University of Melbourne, Parkville, Victoria, Australia; ${ }^{3}$ Cabrini Medical Centre, Malvern, Victoria, Australia; ${ }^{4}$ Department of Haematology, Royal Brisbane and Women's Hospital, Brisbane, Queensland, Australia; ${ }^{5}$ University of Queensland, St Lucia, Queensland, Australia; ${ }^{6}$ Department of Haematology, Monash Health, Clayton, Victoria, Australia and ${ }^{7}$ Department of Haematology, Monash University, Clayton, Victoria, Australia

Background: Central nervous system (CNS) relapse in diffuse large B-cell lymphoma (DLBCL) is a devastating complication; the optimal prophylactic strategy remains unclear.

Methods: We performed a multicentre, retrospective analysis of patients with DLBCL with high risk for CNS relapse as defined by two or more of: multiple extranodal sites, elevated serum LDH and B symptoms or involvement of specific high-risk anatomical sites. We compared three different strategies of CNS-directed therapy: intrathecal (IT) methotrexate (MTX) with (R)-CHOP 'group 1'; R-CHOP with IT MTX and two cycles of high-dose intravenous (IV) MTX 'group 2'; dose-intensive systemic antimetabolitecontaining chemotherapy (Hyper-CVAD or CODOXM/IVAC) with IT/IV MTX 'group 3'.

Results: Overall, 217 patients were identified (49, 125 and 43 in groups 1-3, respectively). With median follow-up of 3.4 (range $0.2-$ 18.6) years, 23 CNS relapses occurred $(12,10$ and 1 in groups $1-3$ respectively). The 3 -year actuarial rates $(95 \% \mathrm{Cl})$ of $\mathrm{CNS}$ relapse were $18.4 \%(9.5-33.1 \%), 6.9 \%(3.5-13.4 \%)$ and $2.3 \%(0.4-15.4 \%)$ in groups $1-3$, respectively $(P=0.009)$.

Conclusions: The addition of high-dose IV MTX and/or cytarabine was associated with lower incidence of CNS relapse compared with IT chemotherapy alone. However, these data are limited by their retrospective nature and warrant confirmation in prospective randomised studies.

Diffuse large B-cell lymphoma (DLBCL) is the most frequent form of non-Hodgkin's lymphoma (Martelli et al, 2013). With current chemoimmunotherapy, $\sim 60 \%$ of patients achieve long-term disease-free survival (Feugier et al, 2005; Swerdlow et al, 2008). With improving systemic disease control, an important mode of treatment failure is secondary involvement of the central nervous system (CNS), a complication that is typically rapidly fatal.

Both the accurate quantification of risk and optimisation of prevention of CNS involvement in patients with DLBCL have been the focus of many studies and several reviews (Ferreri et al, 2009;

*Correspondence: Professor JF Seymour; E-mail: john.seymour@petermac.org

This study has been presented in part at: (1) 49th Annual Exposition of the American Society of Hematology, December 2008. (2) Annual Scientific Meeting of the Haematology Society of Australia and New Zealand, October 2010, 2013. (3) 54th Annual Exposition of the American Society of Hematology, December 2013.

Received 9 April 2014; revised 4 June 2014; accepted 23 June 2014; published online 29 July 2014

(c) 2014 Cancer Research UK. All rights reserved 0007-0920/14 
Herrlinger et al, 2009; Siegal and Goldschmidt, 2012). In an unselected population with DLBCL treated with R-CHOP or similar regimens, the risk of CNS involvement is $4-7 \%$ (van Besien et al, 1998; Zinzani et al, 1999; Hollender et al, 2002; Bjorkholm et al, 2007). This low rate combined with the apparent lack of impact of intrathecal (IT) chemotherapy as prophylaxis has led some to question the value of CNS-directed prophylaxis in the era of R-CHOP primary therapy (Chua et al, 2002; Bernstein et al, 2009; Guirguis et al, 2012; Kumar et al, 2012; Zhang et al, 2014). Despite this, even when treated with $\mathrm{R}-\mathrm{CHOP}$ and IT prophylaxis, a substantial proportion of the truly high-risk population of patients still experience CNS relapse. In an analysis of the large, prospective RICOVER-60 study in which elderly patients with DLBCL were treated with CHOP-14 with or without rituximab, Boehme et al (2009) identified the following factors as independent predictors of CNS relapse risk: elevated serum level of lactate dehydrogenase $(\mathrm{LDH}),>1$ extranodal site of disease and the presence of $\mathrm{B}$ symptoms. The 2-year actuarial risk of CNS relapse for patients with all three risk factors, which comprised $4.8 \%$ of the cohort, was $33.5 \%$. Although neither systematically delivered nor randomly allocated, the use of IT prophylaxis did not significantly reduce the risk of CNS relapse in this cohort, a finding also shown in other studies (Chua et al, 2002; Guirguis et al, 2012; Kumar et al, 2012). It is clear that for these patients a more effective strategy for reducing secondary CNS lymphoma beyond IT chemotherapy alone is needed.

There are several potential explanations for the suboptimal efficacy of IT methotrexate (MTX) alone. IT chemotherapy has poor penetration into brain parenchyma, the site of the majority of CNS relapses (Siegal and Goldschmidt, 2012). Intravenous (IV) MTX achieves more even drug distribution within the neuroaxis than IT administration. (Kimelberg et al, 1977; Balis et al, 2000). Pharmacokinetic studies have shown continuous infusion of IV MTX results in a 'therapeutic' serum level longer than bolus administration (Hryniuk and Bertino, 1969). Hence, there is conceptual appeal to treating patients with doses of MTX and cytarabine capable of penetrating brain parenchyma.

Based on the report by Tilly et al (2003b) showing that the application of CNS prophylaxis with four doses of IT MTX and two courses of IV MTX at $3 \mathrm{~g} \mathrm{~m}^{-2}$ reduced CNS relapse in patients with intermediate grade lymphoma, the CNS prophylaxis strategy for DLBCL at Peter MacCallum Cancer Centre (PMCC) was altered to include high-dose MTX either at the completion of $\mathrm{R}-\mathrm{CHOP}$ therapy or in combination with cytarabine as part of the Hyper-CVAD regimen (Koller et al, 1997). Other Australian institutions subsequently adopted this policy and herein we evaluate the outcome of patients so treated.

\section{PATIENTS AND METHODS}

We conducted a retrospective, multicentre analysis comparing three different forms of therapy on the incidence of CNS relapse in patients with DLBCL judged at high risk of this complication. Patients were identified by searching institutional databases from 1996 to 2011 (to allow a minimum of 2 years of follow-up) for patients with a confirmed histologic diagnosis of DLBCL by WHO criteria (Swerdlow et al, 2008). Patients with DLBCL following histologic transformation of low-grade lymphoma and HIVassociated DLBCL were included; however, patients with Burkitt or Burkitt-like lymphoma and patients with CNS involvement at diagnosis were excluded. Data collection was compliant with local Institutional Review Board requirements at each site. Patients were selected for CNS prophylaxis strategies by their primary managing haematologist if they fulfilled two or more of the following criteria: (1) multiple extranodal sites; (2) elevated serum $\mathrm{LDH}$; (3) or B symptoms. In addition, involvement of specific high-risk anatomical sites, that is, bone marrow (with large cell lymphoma) (Bos et al, 1998), breast (Ryan et al, 2006), testis (Zucca et al, 2003), kidney (Villa et al, 2010), adrenal glands (Tomita et al, 2012), paranasal sinus, nasopharynx, liver and paravertebral (Ferreri et al, 2009) was also considered an indication for CNS prophylaxis.

The features of patients by treatment groups are summarised in Table 1. In brief, from 1991 to 2003, patients received CHOP and IT MTX (group 1). This group also included patients who received MACOP-B \pm rituximab, as the dose of IV MTX is $<1 \mathrm{~g} \mathrm{~m}^{-2}$ and thus unlikely to reach therapeutic levels in brain parenchyma. As previously described, our units adopted a policy of adding highdose IV MTX at different times: PMCC and the Royal Brisbane and Women's (RBWH) in 2003 and Monash Medical Centre (MMC) in 2007. This consisted of $1-3 \mathrm{~g} \mathrm{~m}^{-2}$ (tailored according to renal function) by $24-\mathrm{h}$ continuous IV infusion, followed by leucovorin rescue delivered on days 1 and 15, commencing 2 to 4 weeks after the completion of the $\mathrm{CHOP}-$ like regimen (group 2). Patients $<65$ years of age with age-adjusted IPI of $\geqslant 2$ were treated with dose intensive therapy containing anti-metabolites (HyperCVAD or CODOXM-IVAC, with rituximab after it became available (group 3)). Patients also received IT MTX (12 mg via lumbar puncture) with each cycle of chemotherapy, aiming for a total of six doses unless contraindicated, patients refused or unacceptable toxicity developed. A summary of chemotherapy protocols used can be found in the Appendix.

Central nervous system staging with lumbar puncture and cerebrospinal fluid (CSF) analysis for cytology, flow cytometry (at PMCC, from 2007) and biochemical analysis was typically performed at baseline; however, baseline neuroimaging was typically only performed in the presence of clinical evidence

\begin{tabular}{|c|c|c|c|}
\hline & $\begin{array}{c}\text { Royal Brisbane and Women's } \\
\text { Hospital }\end{array}$ & $\begin{array}{c}\text { Monash Medical } \\
\text { Centre }\end{array}$ & $\begin{array}{c}\text { Peter MacCallum Cancer } \\
\text { Centre }\end{array}$ \\
\hline Number of patients & 35 & 39 & 143 \\
\hline Time period & $2003-2010$ & $2000-2011$ & 1994-2011 \\
\hline Primary chemotherapy (age $<60$ years, aalPI 2,3 ) & R-Hyper-CVAD/R-MA & CODOXM/IVAC & R-Hyper-CVAD/R-MA \\
\hline Primary chemotherapy (all others) & $\mathrm{R}-\mathrm{CHOP}$ & R-CHOP, R-MACOPB & $\mathrm{R}-\mathrm{CHOP}$ \\
\hline Year HD-MTX commenced & 2003 & 2007 & 2003 \\
\hline \multicolumn{4}{|c|}{$\begin{array}{l}\text { Abbreviations: aalPI = age-adjusted international prognostic index; CODOXM/IVAC = cyclophosphamide, vincristine, doxorubicin, methotrexate, ifosfamide, etoposide, cytarabine; HD = high } \\
\text { dose; } \mathrm{R}-\mathrm{CHOP}=\text { rituximab, cyclophosphamide, doxorubicin, vincristine, prednisolone; } \mathrm{R} \text {-HyperCVAD = rituximab, hyperfractionated cyclophosphamide, doxorubicin, vincristine, dexametha- } \\
\text { sone; } \mathrm{R}-\mathrm{MA}=\text { rituximab, high-dose methotrexate, high-dose cytarabine; R-MACOPB = rituximab, methotrexate, doxorubicin, cyclophosphamide, vincristine, prednisolone, bleomicin. See } \\
\text { Appendix for dosage and administration details. }\end{array}$} \\
\hline
\end{tabular}


suggesting CNS lymphoma or positive CSF cytology or flow cytometry. The CNS involvement was defined by one or more of (1) histologically confirmed CNS involvement; (2) neuroimaging findings compatible with CNS involvement with lymphoma, in conjunction with consistent clinical presentation and the absence of other clinically feasible diagnosis; or (3) positive CSF (lymphoma cells detected by cytology and/or flow-cytometry).

Statistical analysis. Continuous variables are expressed as median and range and compared using the Mann-Whitney $U$-test. Categorical variables are reported as proportions, and compared using $\chi^{2}$ or Kruskal-Wallis tests, as appropriate. Progression-free survival (PFS), overall survival (OS) and time to CNS relapse were determined from date of diagnosis using the method of Kaplan and Meier (1958) and compared using log-rank analysis. An 'event' for PFS was defined by CNS or systemic relapse, or death from any cause. Cumulative incidence of CNS relapse was calculated using the Kaplan-Meier method and competing risk regression analysis using Fine and Gray's proportional hazard model (Fine and Gray, 1999). In this analysis, death without CNS relapse was defined as the competing risk. Statistical analysis was performed using STATA version 12.1 (Statacorp, College Station, TX, USA) and any $P$-value of $<0.05$ was considered significant.

\section{RESULTS}

We identified 217 patients with DLBCL judged as high risk for CNS involvement by the stated criteria. A total of 35 patients (15\%) were treated at RBWH, $39(18 \%)$ at MMC and $143(69 \%)$ at PMCC. Group 1 (reference) was drawn from PMCC and MMC, whereas all centres contributed cases to groups 2 and 3. The baseline characteristics of patients in the three groups are summarised in Table 2. Fewer patients in group 1 received rituximab given the timeframe of its availability within Australia and. as expected. patients selected for intensive approaches (group 3) were younger and had higher risk disease features (higher normalised serum LDH, B symptoms). The distribution of extranodal sites for each of the three groups was similar, with a nonsignificant trend towards greater frequency of epidural/ paraspinal disease in group 1. The majority of patients (84\%) underwent baseline CSF analysis; the remaining 16\% had no clinical evidence of CNS involvement at baseline and the first available CSF cytology was negative. The proportion of patients without baseline CSF analysis was similar between the three groups.

CNS prophylaxis. In group 2, 109 (80\%) received both intended cycles of systemic high-dose MTX, with 25 (20\%) receiving only one (for reasons described under 'toxicity' below). For patients in group 2, the median length of inpatient admission to receive highdose IV MTX was 4 (range 2-16) days per cycle. Compliance with planned IT MTX was high, with a median of 5, 6 and 5 doses of IT MTX in groups 1-3 respectively. All patients in group 1 received at least one dose of IT MTX, compared with $81 \%$ and $85 \%$ of patients in groups 2 and 3 respectively $(P=0.005)$.

Outcomes. The median follow-up in the entire cohort was 3.4 (range 0.2-18.6) years. Among groups 1-3, the median follow-up was 5.8, 3.0 and 3.8 years, respectively. During this time, $23 \mathrm{CNS}$ relapses have occurred (12, 10 and 1 in groups $1-3$, respectively). The median time to CNS relapse was 10.8 (range 4-109.6) months from initial diagnosis. The number and distribution of CNS relapses, 3-year cumulative incidence rates of CNS relapse and OS by treatment group are displayed in Table 3 and Figures 1 and 2 . Briefly, the CNS relapse risk was highest in group $1(P=0.006)$. Although the CNS relapse risk appeared numerically lower in group 3 compared with group 2, direct comparison between the two showed no statistically significant difference $(P=0.16)$. The actuarial 3-year PFS rates were 65.5\% (49.8-77.3\%), $82.9 \%$ $(74.7-88.6 \%)$ and $70.6 \%(53.9-82.2 \%)$ in groups $1-3$, respectively $(P=0.051$, Figure 3$)$. Isolated CNS relapse (in the absence of systemic relapse) occurred in 20 out of 23 (87\%) patients with CNS relapse, with the remaining $3(12 \%)$ occurring in conjunction with systemic relapse. Of the 17 patients with sufficient data, the distribution of CNS relapses was leptomeningeal alone in 6 (35\%), parenchymal alone in $9(53 \%)$ and both in $2(12 \%)$ patients. The pattern of localisation did not differ between groups $(P=0.16$, Table 3). While recognising that all patients were considered to be at high risk for CNS relapse, we explored several potential risk factors identified in other studies (van Besien et al, 1998; Haioun et al, 2000; Shimazu et al, 2009; Schmitz et al, 2012). By univariate analysis, the only factor affecting CNS relapse risk was treatment group (Table 4). We also performed a multivariate analysis that included treatment group, use of rituximab, age $>60$ years, ECOG $\geqslant 2$, IPI $\geqslant 3$, raised serum $\mathrm{LDH}, \mathrm{B}$ symptoms, multiple extranodal sites, paraspinal disease and treatment era (dichotomised at 2000) - only treatment group affected CNS relapse (Table 5). The hazard ratio (HR) for group 2 was $0.26(95 \%$ CI $0.08-0.81, P=0.02)$ and for group 3 was $0.07(0.01-0.55, P=0.01)$. Number of doses of IT MTX did not affect the risk of CNS relapse (HR for 4 or more doses compared with 3 or less 0.84 (95\% CI 0.29-2.40, $P=0.75$ ).

Impact of rituximab. In total, 159 out of 217 (73\%) patients received rituximab as part of induction therapy. Nearly all patients in group 2, but only $37 \%$ and $42 \%$ of patients in groups 1 and 3 , received rituximab. However, use of rituximab had no impact on CNS relapse when all groups were considered collectively (HR 0.62, 95\% CI $0.27-1.44, P=0.27$ ), and when considering the impact within groups 1 and 3 , there was no difference in CNS relapse ( $P=0.28$ and $P=0.24$, respectively, data not shown).

Toxicity (described for patients in group 2 only). Despite routine urinary alkalinisation, the most frequent toxicity of systemic MTX was renal impairment of any grade, occurring in $70 \%$ of cycles overall, the majority (55\%) grade 1 in severity. Most of these events were minor and transient elevations of serum creatinine without clinical consequences. In two cases, grade 1 renal impairment was associated with delayed MTX clearance (defined as $>5$ days). Grade 2 renal impairment occurred in 14\% of cycles and grades 3 and 4 were rare $(<1 \%)$. All patients recovered renal function without need for haemodialysis. The second cycle was omitted in 20 cases because of renal impairment and delayed MTX clearance $(n=8)$, grade $3+$ alanine transaminase (ALT) elevation $(n=3)$, CNS toxicity $(n=1)$, sepsis $(n=2)$ and reason not specified $(n=4)$. Dose reductions for the second cycle occurred in 11 out of 104 patients $(10.6 \%)$ because of renal impairment $(n=4)$, painful neuropathy $(n=1)$, delayed clearance with normal renal function $(n=1)$ and reason not documented $(n=4)$. Asymptomatic elevation of ALT resolved in all cases spontaneously without complication.

\section{DISCUSSION}

While acknowledging the limitations of this retrospective analysis, in a group of patients specifically selected for high risk of CNS relapse, the addition of high-dose IV MTX with or without cytarabine was associated with a reduction in the rate of subsequent CNS relapse. The actuarial 3-year risk of CNS relapse was $18.4 \%$ in patients who received $\mathrm{CHOP} \pm \mathrm{R}$ with IT MTX; $6.9 \%$ in patients who received $\mathrm{CHOP} \pm \mathrm{R}$, IT MTX and high-dose IV MTX; and $2.3 \%$ in patients receiving chemotherapy regimens containing high-dose IV MTX and cytarabine $(P=0.009)$. The nonsignificant trend towards lower incidence of CNS relapse seen in group 3 vs 2 may reflect the high dose of cytarabine 


\begin{tabular}{|c|c|c|c|c|}
\hline & Group 1 & Group 2 & Group 3 & \\
\hline & $\begin{array}{c}\mathrm{CHOP} \pm \mathrm{R} \\
\text { intrathecal } \mathrm{MTX}\end{array}$ & $\begin{array}{l}\mathrm{R} \pm \text { CHOP-like chemo } \\
+ \text { high-dose IV MTX }\end{array}$ & $\begin{array}{c}\text { HyperCVAD or CODOXM/ } \\
\text { IVAC } \pm \text { rituximab }\end{array}$ & $P$-value \\
\hline Patients & $49(23 \%)$ & $125(58 \%)$ & $43(20 \%)$ & - \\
\hline Centres contributing & PMCC, MMC & $\mathrm{RBH}, \mathrm{MMC}, \mathrm{PMCC}$ & $\mathrm{RBH}, \mathrm{MMC}, \mathrm{PMCC}$ & \\
\hline Time period & 1992-2007 & 2003-2011 & 1991-2011 & \\
\hline Median age, years (range) & $54.5(19-84)$ & $63(23-84)$ & $45(16-74)$ & $<0.0001$ \\
\hline Male (\%) & $33 / 49(67 \%)$ & $81 / 125$ (65\%) & $24 / 43(57 \%)$ & 0.78 \\
\hline Stage III/IV (\%) & $35 / 48(73 \%)$ & 104/125 (84\%) & $38 / 43(88 \%)$ & 0.18 \\
\hline B symptoms & $16 / 48$ (33\%) & 43/106 (41\%) & $27 / 42$ (64\%) & 0.007 \\
\hline Median normalised serum LDH (range) & $1.3(0.3-6.0)$ & $1.2(0.3-11.4)$ & $1.6(0.7-25.7)$ & $<0.0001$ \\
\hline$E C O G P S \geqslant 2$ & $12 / 48(25 \%)$ & $25 / 122(20 \%)$ & $12 / 42(29 \%)$ & 0.53 \\
\hline Transformed histology & $2 / 49$ (4\%) & $17 / 124(14 \%)$ & $3 / 43(7 \%)$ & 0.15 \\
\hline IPI 3-5 & $23 / 48(48 \%)$ & $82 / 122(67 \%)$ & $27 / 42(66 \%)$ & 0.06 \\
\hline Extranodal sites $\geqslant 2$ & $23 / 49(47 \%)$ & $71 / 122(58 \%)$ & $20 / 43(47 \%)$ & 0.27 \\
\hline \multicolumn{5}{|l|}{ Specific extranodal sites } \\
\hline $\begin{array}{l}\text { Bone marrow } \\
\text { Bone } \\
\text { Breast } \\
\text { Ovary } \\
\text { Testes } \\
\text { Renal } \\
\text { Hepatic } \\
\text { Paranasal sinuses } \\
\text { Nasopharnyx } \\
\text { Bowel } \\
\text { Epidural/paraspinal }\end{array}$ & $\begin{array}{l}17(35 \%) \\
15(31 \%) \\
2(4 \%) \\
1(2 \%) \\
3(6 \%) \\
3(6 \%) \\
6(12 \%) \\
1(2 \%) \\
0(0 \%) \\
1(2 \%) \\
5(10 \%)\end{array}$ & $\begin{array}{c}34(27 \%) \\
34(27 \%) \\
4(3 \%) \\
2(2 \%) \\
8(6 \%) \\
8(6 \%) \\
21(17 \%) \\
7(6 \%) \\
3(2 \%) \\
8(6 \%) \\
7(6 \%)\end{array}$ & $\begin{array}{l}15(35 \%) \\
16(38 \%) \\
0(0 \%) \\
3(7 \%) \\
2(5 \%) \\
1(2 \%) \\
7(16 \%) \\
1(2 \%) \\
0(0 \%) \\
1(2 \%) \\
0(0 \%)\end{array}$ & $\begin{array}{l}0.47 \\
0.41 \\
0.45 \\
0.16 \\
0.94 \\
0.60 \\
0.75 \\
0.47 \\
0.33 \\
0.35 \\
0.09\end{array}$ \\
\hline Chemotherapy & $\begin{array}{c}\text { CHOP } 31 \\
\text { R-CHOP } 11^{*} \\
\text { R-MACOPB } 7\end{array}$ & $\begin{array}{c}\text { CHOP } 3 \\
\text { R-CHOP } 122\end{array}$ & $\begin{array}{l}\text { Hyper CVAD } 22 \\
\text { R-Hyper CVAD } 16 \\
\text { R-CODOXMIVAC } 2 \\
\text { CODOXMIVAC } 1 \\
\text { MVP } 1\end{array}$ & \\
\hline Rituximab & $18 / 49(37 \%)$ & $123 / 125$ (98\%) & $18 / 43(42 \%)$ & $<0.0001$ \\
\hline \multicolumn{5}{|l|}{ IT methotrexate (any) } \\
\hline Median number Doses (range) & $\begin{array}{c}49 / 49(100 \%) \\
5(1-6)\end{array}$ & $\begin{array}{l}84 / 104(81 \%) \\
\quad 6(0-7)\end{array}$ & $\begin{array}{l}28 / 33(85 \%) \\
5(0-6)\end{array}$ & 0.005 \\
\hline \multicolumn{5}{|c|}{ 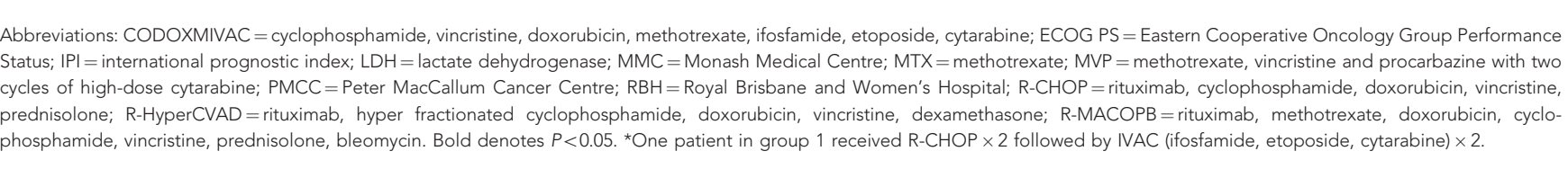 } \\
\hline
\end{tabular}

administered to these patients, or potentially superior systemic disease control, as fewer systemic relapses occurred in the group 3. Although three patients in group 3 received CODOXM IVAC $\pm \mathrm{R}$ (which contains both high-dose cytarabine and ifosfamide), the low numbers make it difficult to comment meaningfully on their effect on CNS relapse. The high relapse rate in patients treated with IT alone support findings from other studies that this approach is inadequate (Chua et al, 2002; Boehme et al, 2009; Villa et al, 2010; Tai et al, 2011). Over $60 \%$ of CNS relapses involved brain parenchyma and were not prevented by IT chemotherapy alone. In fact, there was a nonsignificant trend towards fewer leptomeningeal relapses in patients who received prophylaxis with IV MTX. This result is difficult to explain, however, it should be noted that the total number of CNS relapses was low and $>80 \%$ of patients in groups 2 and 3 also received IT MTX.
Soon after two of our institutions changed policy to incorporate IV MTX for CNS prophylaxis in 2003, rituximab was reimbursed for the treatment of patients with DLBCL in Australia in 2005. This coincidence accounts for the imbalance in rituximab use between groups. The published data dealing with the impact of rituximab on CNS relapse are mixed - some studies have shown no impact (Feugier et al, 2005; Yamamoto et al, 2010; Miyazaki et al, 2011; Tai et al, 2011) whereas others have shown a significant reduction (Shimazu et al, 2009; Villa et al, 2010; Mitrovic et al, 2012). A meta-analysis of pooled data from eight studies comparing rituximab with chemotherapy with chemotherapy alone found that addition of rituximab slightly reduced the risk of CNS relapse from $5.7 \%$ to $4.7 \%$ (Zhang et al, 2014). In our analysis, the use of rituximab as part of induction therapy did not appear to influence the risk of CNS relapse either in the cohort as a whole or when 
Table 3. Overall and CNS relapse-free survival by group

\begin{tabular}{|c|c|c|c|c|}
\hline & Group 1 & Group 2 & Group 3 & \\
\hline & $\mathrm{CHOP} \pm \mathrm{R}+\mathrm{IT} \mathrm{MTX}$ & $\begin{array}{c}\mathrm{CHOP} \pm \mathrm{R}+\mathrm{IT} \\
\text { MTX }\end{array}$ & $\begin{array}{l}\text { HyperCVAD or } \\
\text { CODOXMIVAC } \pm R\end{array}$ & $P$-value \\
\hline Number & 12 & 10 & 1 & - \\
\hline \multicolumn{5}{|l|}{ Localisation } \\
\hline $\begin{array}{l}\text { Leptomeningeal } \\
\text { Parenchymal } \\
\text { Both } \\
\text { Unknown }\end{array}$ & $\begin{array}{l}5 \\
4 \\
2 \\
1\end{array}$ & $\begin{array}{l}1 \\
5 \\
0 \\
4\end{array}$ & $\begin{array}{l}0 \\
0 \\
0 \\
1\end{array}$ & 0.16 \\
\hline $\begin{array}{l}\text { 3-Year cumulative incidence of CNS } \\
\text { relapse }(95 \% \mathrm{Cl})\end{array}$ & $\begin{array}{c}18.4 \% \\
(9.5-33.1 \%)\end{array}$ & $\begin{array}{c}6.9 \% \\
(3.5-13.4 \%)\end{array}$ & $\begin{array}{c}2.3 \% \\
(0.3-15.4 \%)\end{array}$ & 0.009 \\
\hline 3-Year overall survival & $\begin{array}{c}68.0 \% \\
(52.4-79.3 \%)\end{array}$ & $\begin{array}{c}85.9 \% \\
(77.6-91.3 \%)\end{array}$ & $\begin{array}{c}89.2 \% \\
(73.7-95.8 \%)\end{array}$ & 0.029 \\
\hline
\end{tabular}

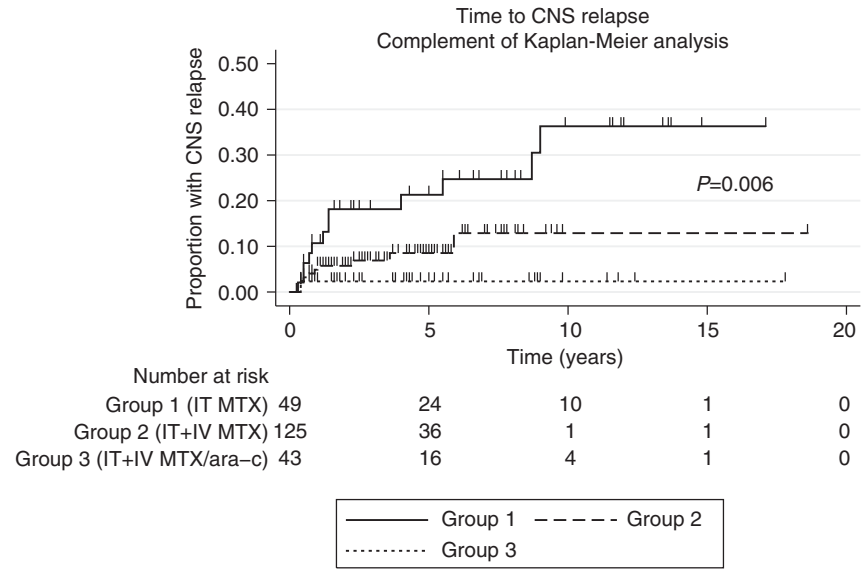

Figure 1. Cumulative incidence of CNS relapse using the complement of the Kaplan-Meier method, by treatment group.

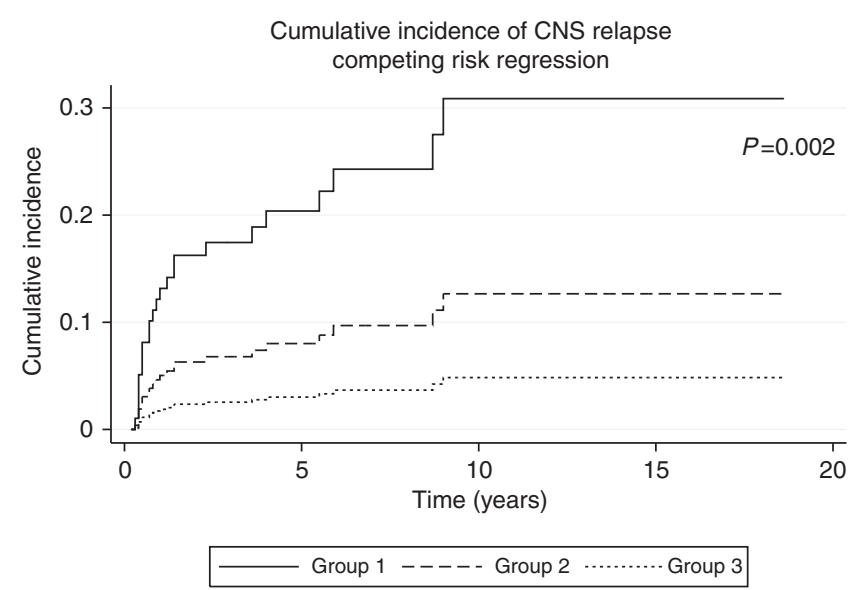

Figure 2. Cumulative incidence of CNS relapse with death as a competing risk by treatment group, using the method of Fine and Gray (1999).

subgroup analyses were performed within groups 1 and 3 . Therefore, we conclude that the impact from the lack of rituximab in group 1 is likely to be modest and does not completely account for the marked

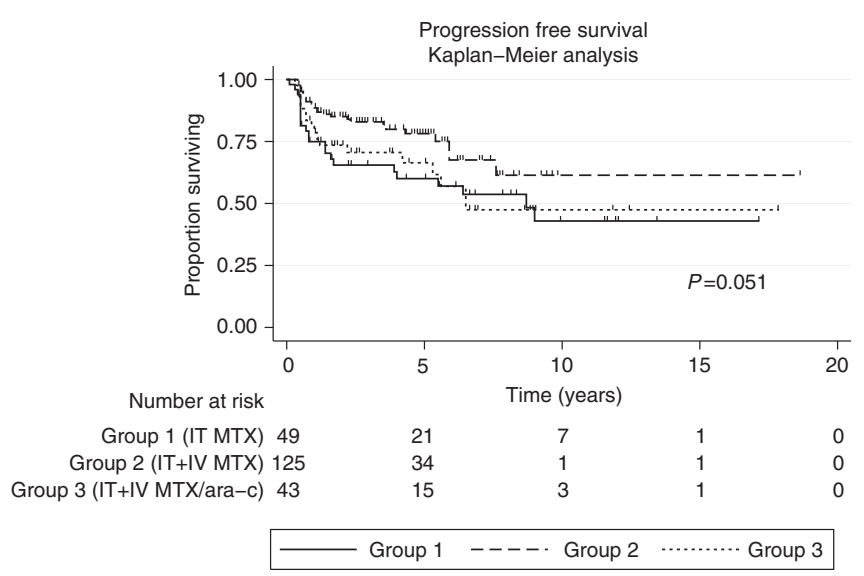

Figure 3. Progression-free survival by treatment group.

difference in CNS relapse risk seen. There were some imbalances in CNS risk factors between the groups: group 3 were younger, had higher serum LDH and more patients with B symptoms. In spite of this, the risk of CNS relapse was lowest in this group.

High-dose IV MTX is not without disadvantages. It is administered in an in-patient setting at our institutions, and has both financial and physical resource implications. Although grade $3+$ adverse events were rare, despite careful fluid management and urinary alkalinisation, grade $2+$ renal impairment occurred in $15 \%$ of patients. Although no patients developed irreversible renal impairment or need for haemodialysis, in $8 \%$ of cycles the renal impairment resulted in delayed MTX clearance and prolonged hospitalisation. The optimal schedule for delivery of high-dose IV MTX remains unclear and both shorter and 24-h infusion times are used, with both appearing to have utility (Joerger et al, 2012).

A few other studies have been performed that suggest that highdose anti-metabolite therapy provides effective CNS prophylaxis in patients with DLBCL (Tilly et al, 2003a; Abramson et al, 2010; Holte et al, 2013). Tilly et al (2003b) conducted a prospective comparison between ACVBP and CHOP for intermediate grade lymphoma. The ACVBP regimen included a consolidation phase (IV MTX $3 \mathrm{~g} \mathrm{~m}^{-2}$ ) and four doses of IT MTX. Although stratification by CNS risk was not prespecified, the randomisation resulted in balanced distribution of CNS risk features (such as 
Table 4. Cox regression univariate analysis of risk factors for CNS relapse among patients selected for high risk of this complication

\begin{tabular}{|c|c|c|}
\hline Risk factor (univariate) & HR (95\% Cl) Cox & $P$-value \\
\hline Age $>60$ years & $1.22(0.53-2.82)$ & 0.64 \\
\hline Stage III/IV & $1.49(0.44-5.06)$ & 0.50 \\
\hline Histologic transformation & $0.84(0.20-3.62)$ & 0.82 \\
\hline ECOG performance status $\geqslant 2$ & $1.78(0.75-4.28)$ & 0.21 \\
\hline Serum LDH >ULN & $1.28(0.52-3.14)$ & 0.59 \\
\hline Multiple extranodal sites & $1.50(0.65-3.47)$ & 0.34 \\
\hline IPI 3-5 & $2.38(0.87-6.47)$ & 0.068 \\
\hline B symptoms & $0.71(0.28-1.80)$ & 0.47 \\
\hline Paraspinal disease & $1.38(0.41-4.67)$ & 0.61 \\
\hline Group 1 group 2 (high-dose IV MTX) & NA (Reference) & - \\
\hline Group 3 (high-dose IV MTX-ara-c) & $0.38(0.16-0.91)$ & 0.03 \\
\hline Rituximab & $0.10(0.01-0.76)$ & 0.03 \\
\hline Number of doses of IT MTX ( $\geqslant 4$ vs $0-3$ ) & $1.21(0.48-3.05)$ & 0.69 \\
\hline $\begin{array}{l}\text { Decade of treatment (1990-2000 vs } 2000 \\
\text { onwards) }\end{array}$ & $\begin{array}{l}0.84(0.29-2.40) \\
0.85(0.30-2.30)\end{array}$ & $\begin{array}{l}0.75 \\
0.75\end{array}$ \\
\hline \multicolumn{3}{|c|}{ 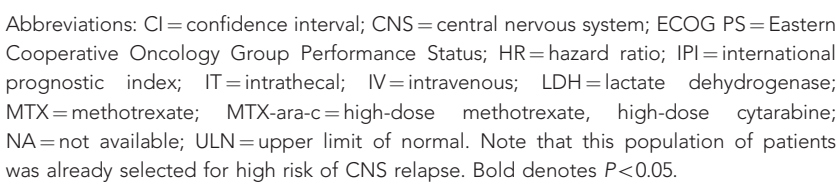 } \\
\hline
\end{tabular}

Table 5. Cox regression multivariate analysis of risk factors for CNS relapse among patients selected for high risk of this complication

\begin{tabular}{|l|c|c|}
\hline Risk factor (multivariate) & $\mathrm{HR}(95 \% \mathrm{Cl})$ Cox & $\boldsymbol{P}$-value \\
\hline Group 2 (high-dose IV MTX) & $0.26(0.08-0.81)$ & 0.02 \\
\hline Group 3 (high-dose IV MTX-ara-c) & $0.07(0.01-0.55)$ & 0.01 \\
\hline $\begin{array}{l}\text { Abbreviations: Cl= confidence interval; CNS = central nervous system; HR= hazard ratio; } \\
\text { IV=intravenous; MTX=methotrexate; MTX-ara-c=high-dose methotrexate, high-dose } \\
\text { cytarabine. }\end{array}$ \\
\hline
\end{tabular}

raised serum LDH and multiple extranodal sites) between arms. Patients treated with ACVBP (which included both IT and highdose IV MTX) had CNS relapse risk of $2.8 \%$ compared with $8.3 \%$ in patients treated with CHOP alone $(P=0.004)$ (Tilly et al, 2003b). The follow-up LNH03-2B study was a randomised phase III comparison between R-ACVBP and eight cycles of R-CHOP21 (with four doses of IT MTX) in patients with DLBCL, aaIPI $\geqslant 1$ aged 18-65years (Recher et al, 2011). Patients in this study were neither specifically selected nor stratified for CNS relapse risk, and the low incidence of CNS relapse overall (0 out of $192(0 \%)$ for R-ACVBP vs 2 out of 183 (1\%) for R-CHOP) makes it difficult to draw conclusions regarding the effectiveness of the MTX in this study (Recher et al, 2011). It is worth noting that the ACVBP regimen also contains four cycles of ifosfamide, an agent that is known to penetrate the CSF in patients with CNS tumours (although CNS penetration of its metabolite, 4-OH-ifosfamide is more variable) (Kiewe et al, 2011). Therefore, it is possible that this agent may be partly responsible for the reduction in CNS relapse seen in patients treated with ACVBP. Abramson et al (2010) treated 65 patients with high risk for CNS involvement as defined by published risk models (van Besien et al, 1998; Haioun et al,
2000; Hollender et al, 2002) or high-risk extranodal sites. Patients were treated with a median of three cycles of MTX at a dose of $3.5 \mathrm{~g} \mathrm{~m}^{-2}$ but only four (6\%) patients received a dose of IT MTX at the time of diagnostic LP. Despite this, after a median follow-up of 33 months, only two patients had developed CNS relapse, with a resultant estimated CNS recurrence rate of 3\%. Holte et al (2013) conducted a phase II study of young, high-risk patients (aged $<65$ years, age-adjusted IPI 2-3) in which the treatment protocol was specifically designed to minimise CNS relapse. Patients were treated with rituximab, cyclophosphamide, doxorubicin, etoposide and prednisolone (R-CHOEP14) followed by four doses of IV cytarabine (2-3 $\left.\mathrm{g} \mathrm{m}^{-2}\right)$ and one cycle of MTX (1.5-3 $\left.\mathrm{g} \mathrm{m}^{-2}\right)$. They treated 156 patients and found the toxicity manageable (grade 3/4 haematological $79 \%$, grade $3 / 4$ infections $7 \%$ ) and deliverable. With a median follow-up of 52 months, seven CNS relapses have occurred, a crude incidence of $4.5 \%$-lower than might be expected in a high-risk population.

It should be noted that flow cytometric analysis of CSF was not uniformly performed at baseline at all centres; this policy was adopted from 2007 at PMCC. Seven patients developed CNS relapse within 6 months of diagnosis. We acknowledge that occult CNS involvement at baseline in these patients may not have been detected; however, the distribution of cases with missing baseline CSF cytology did not differ between treatment groups. Recently, many groups have incorporated both more rigorous baseline CNS staging (with mandatory CSF flow cytometric analysis) and earlier CNS-directed therapies (both systemic and IT) into future treatment protocols (Holte et al, 2013).

The optimal timing of systemic high-dose chemotherapy as CNS prophylaxis is a critical unresolved question. Studies have consistently shown that CNS relapse is most frequent in the first 12 months from completion of primary therapy (Haioun et al, 2000; Tilly et al, 2003a; Feugier et al, 2004; Bernstein et al, 2009; Lee et al, 2009; Villa et al, 2010; Yamamoto et al, 2010; Tai et al, 2011). This pattern of early CNS failures suggests occult CNS disease present at diagnosis and has led some groups, such as the German High Grade Lymphoma Study Group, to incorporate the first dose of systemic high-dose MTX before the commencement of chemoimmunotherapy, during steroid prephase (M Pfreundschuh, personal communication). Although providing early CNS prophylaxis, such scheduling risks delaying chemoimmunotherapy if toxicity occurs. Given the paucity of comparative data evaluating the efficacy of differing doses and timing of administration of systemic antimetabolite therapy for CNS prophylaxis, it is clear that these remain contentious issues.

The major limitation of this study lies in the retrospective nature, and heterogeneity in baseline risk and treatment factors (particularly rituximab) among the three groups, leading to potential bias. Nonetheless, this finding adds to the growing body of nonrandomised data suggesting that incorporation of high-dose IV MTX \pm cytarabine into treatment protocols may lower the risk of CNS relapse in patients with DLBCL at high risk of the complication. Ideally, this hypothesis would be tested in an adequately powered, prospective study randomising patients to R-CHOP + IT MTX \pm high-dose IV MTX and/or cytarabine, with the primary end point 2-year rate of CNS relapse. There are, however, several practical difficulties with performing such a study. Many clinicians believe sufficient evidence exists to support the efficacy of high-dose IV MTX \pm cytarabine for CNS-directed prophylaxis and may be uncomfortable enrolling patients to a protocol with a chance of not receiving it. Second, because CNS relapse remains a rare complication, adequately powering a study is costly and difficult. Limiting the study to only high-risk patients (with estimated CNS relapse risk of $\sim 15 \%$ ) would reduce the sample size needed, but such patients comprise $<10 \%$ of DLBCL overall (Schmitz et al, 2013). This probably explains why a prospective study addressing this question has yet to be completed to our knowledge. 


\section{CONCLUSION}

The addition of high-dose IV MTX, either at the completion of $\mathrm{R}-\mathrm{CHOP}$ or as part of dose-intensive chemotherapy strategies, is associated with a reduction in CNS relapse risk in DLBCL. This finding should ideally be tested in prospective, randomised studies.

\section{ACKNOWLEDGEMENTS}

This study was funded in part by the Victorian Cancer Agency Grant Number CTCB11_18 and the Haematology Society of Australia and New Zealand (New Investigator Scholarship).

\section{CONFLICT OF INTEREST}

The authors declare no conflict of interest.

\section{AUTHOR CONTRIBUTIONS}

CYC collected and analysed data and wrote the manuscript; $\mathrm{KEH}$, KO'R, MG, AG, GAK, PF, SYT, SSO, DSR, HMP, MD, KB, DW, MW, EHJ, DAC and SJH contributed patients and collected data; JFS designed the study, analysed data and co-wrote the manuscript. All authors participated in manuscript revision and approved the final version.

\section{REFERENCES}

Abramson JS, Hellmann M, Barnes JA, Hammerman P, Toomey C, Takvorian T, Muzikansky A, Hochberg EP (2010) Intravenous methotrexate as central nervous system (CNS) prophylaxis is associated with a low risk of CNS recurrence in high-risk patients with diffuse large B-cell lymphoma. Cancer 116(18): 4283-4290.

Balis FM, Blaney SM, McCully CL, Bacher JD, Murphy RF, Poplack DG (2000) Methotrexate distribution within the subarachnoid space after intraventricular and intravenous administration. Cancer Chemother Pharmacol 45(3): 259-264.

Bernstein SH, Unger JM, Leblanc M, Friedberg J, Miller TP, Fisher RI (2009) Natural history of CNS relapse in patients with aggressive non-Hodgkin's lymphoma: a 20-year follow-up analysis of SWOG 8516 - the Southwest Oncology Group. J Clin Oncol 27(1): 114-119.

Bjorkholm M, Hagberg H, Holte H, Kvaloy S, Teerenhovi L, Anderson H, Cavallin-Stahl E, Myhre J, Pertovaara H, Ost A, Nilsson B, Osby E (2007) Central nervous system occurrence in elderly patients with aggressive lymphoma and a long-term follow-up. Ann Oncol 18(6): 1085-1089.

Boehme V, Schmitz N, Zeynalova S, Loeffler M, Pfreundschuh M (2009) CNS events in elderly patients with aggressive lymphoma treated with modern chemotherapy (CHOP-14) with or without rituximab: an analysis of patients treated in the RICOVER-60 trial of the German High-Grade Non-Hodgkin Lymphoma Study Group (DSHNHL). Blood 113(17): 3896-3902.

Bos GM, van Putten WL, van der Holt B, van den Bent M, Verdonck LF, Hagenbeek A (1998) For which patients with aggressive non-Hodgkin's lymphoma is prophylaxis for central nervous system disease mandatory? Dutch HOVON Group. Ann Oncol 9(2): 191-194.

Chua SL, Seymour JF, Streater J, Wolf MM, Januszewicz EH, Prince HM (2002) Intrathecal chemotherapy alone is inadequate central nervous system prophylaxis in patients with intermediate-grade non-Hodgkin's lymphoma. Leuk Lymphoma 43(9): 1783-1788.

Ferreri AJ, Assanelli A, Crocchiolo R, Ciceri F (2009) Central nervous system dissemination in immunocompetent patients with aggressive lymphomas: incidence, risk factors and therapeutic options. Hematol Oncol 27(2): 61-70.

Feugier P, Van Hoof A, Sebban C, Solal-Celigny P, Bouabdallah R, Ferme C, Christian B, Lepage E, Tilly H, Morschhauser F, Gaulard P, Salles G, Bosly A,
Gisselbrecht C, Reyes F, Coiffier B (2005) Long-term results of the R-CHOP study in the treatment of elderly patients with diffuse large B-cell lymphoma: a study by the Groupe d'Etude des Lymphomes de l'Adulte. J Clin Oncol 23(18): 4117-4126.

Feugier P, Virion JM, Tilly H, Haioun C, Marit G, Macro M, Bordessoule D, Recher C, Blanc M, Molina T, Lederlin P, Coiffier B (2004) Incidence and risk factors for central nervous system occurrence in elderly patients with diffuse large-B-cell lymphoma: influence of rituximab. Ann Oncol 15(1): 129-133.

Fine JP, Gray RJ (1999) A proportional hazards model for the subdistribution of a competing risk. J Am Stat Assoc 94(446): 496-509.

Guirguis HR, Cheung MC, Mahrous M, Piliotis E, Berinstein N, Imrie KR, Zhang L, Buckstein R (2012) Impact of central nervous system (CNS) prophylaxis on the incidence and risk factors for CNS relapse in patients with diffuse large B-cell lymphoma treated in the rituximab era: a single centre experience and review of the literature. Br J Haematol 159(1): 39-49.

Haioun C, Besson C, Lepage E, Thieblemont C, Simon D, Rose C, Tilly H, Sonet A, Lederlin P, Attal M, Briere J, Reyes F (2000) Incidence and risk factors of central nervous system relapse in histologically aggressive non-Hodgkin's lymphoma uniformly treated and receiving intrathecal central nervous system prophylaxis: a GELA study on 974 patients. Groupe d'Etudes des Lymphomes de l'Adulte. Ann Oncol 11(6): 685-690.

Herrlinger U, Glantz M, Schlegel U, Gisselbrecht C, Cavalli F (2009) Should intra-cerebrospinal fluid prophylaxis be part of initial therapy for patients with non-Hodgkin lymphoma: what we know, and how we can find out more. Semin Oncol 36(4 Suppl 2): S25-S34.

Hollender A, Kvaloy S, Nome O, Skovlund E, Lote K, Holte H (2002) Central nervous system involvement following diagnosis of non-Hodgkin's lymphoma: a risk model. Ann Oncol 13(7): 1099-1107.

Holte H, Leppä S, Björkholm M, Fluge Ø, Jyrkkiö S, Delabie J, Sundström C, Karjalainen-Lindsberg M-L, Erlanson M, Kolstad A, Fosså A, Østenstad B, Löfvenberg E, Nordström M, Janes R, Pedersen LM, Anderson H, Jerkeman M, Eriksson M (2013) Dose-densified chemoimmunotherapy followed by systemic central nervous system prophylaxis for younger highrisk diffuse large B-cell/follicular grade 3 lymphoma patients: results of a phase II Nordic Lymphoma Group study. Ann Oncol 24(5): 1385-1392.

Hryniuk WM, Bertino JR (1969) Treatment of leukemia with large doses of methotrexate and folinic acid: clinical-biochemical correlates. J Clin Invest 48(11): 2140-2155.

Joerger M, Huitema AD, Illerhaus G, Ferreri AJ (2012) Rational administration schedule for high-dose methotrexate in patients with primary central nervous system lymphoma. Leuk Lymphoma 53(10): 1867-1875.

Kaplan EL, Meier P (1958) Nonparametric estimation from incomplete observations. J Am Stat Assoc 53(282): 457-481.

Kiewe P, Neumann M, Wagner T, Seyfert S, Albrecht H, Thiel E, Korfel A (2011) Penetration of ifosfamide and its active metabolite 4-OHifosfamide into cerebrospinal fluid of patients with CNS malignancies. Cancer Chemother Pharmacol 67(1): 27-33.

Kimelberg HK, Biddlecome SM, Bourke RS (1977) Distribution and degradation of $[3 \mathrm{H}]$ methotrexate after intravenous and cerebral intraventricular injection in primates. Cancer Res 37(1): 157-165.

Koller CA, Kantarjian HM, Thomas D, O’Brien S, Rios MB, Kornblau S, Murphy S, Keating M (1997) The hyper-CVAD regimen improves outcome in relapsed acute lymphoblastic leukemia. Leukemia 11(12): 2039-2044.

Kumar A, Vanderplas A, LaCasce AS, Rodriguez MA, Crosby AL, Lepisto E, Czuczman MS, Nademanee A, Niland J, Gordon LI, Millenson M, Zelenetz AD, Friedberg JW, Abel GA (2012) Lack of benefit of central nervous system prophylaxis for diffuse large B-cell lymphoma in the rituximab era: findings from a large national database. Cancer 118(11): 2944-2951.

Lee KW, Yi J, Choi IS, Kim JH, Bang SM, Kim DW, Im SA, Kim TY, Yoon SS, Lee JS, Bang YJ, Park S, Kim BK, Cho HI, Heo DS (2009) Risk factors for poor treatment outcome and central nervous system relapse in diffuse large B-cell lymphoma with bone marrow involvement. Ann Hematol 88(9): 829-838.

Martelli M, Ferreri AJ, Agostinelli C, Di Rocco A, Pfreundschuh M, Pileri SA (2013) Diffuse large B-cell lymphoma. Crit Rev Oncol Hematol 87(2): $146-171$.

Mitrovic Z, Bast M, Bierman PJ, Bociek RG, Vose JM, Chan WC, Armitage JO (2012) The addition of rituximab reduces the incidence of secondary central nervous system involvement in patients with diffuse large B-cell lymphoma. Br J Haematol 157(3): 401-403. 
Miyazaki K, Yamaguchi M, Suzuki R, Kobayashi Y, Maeshima AM, Niitsu N, Ennishi D, Tamaru JI, Ishizawa K, Kashimura M, Kagami Y, Sunami K, Yamane H, Nishikori M, Kosugi H, Yujiri T, Hyo R, Katayama N, Kinoshita T, Nakamura S (2011) CD5-positive diffuse large B-cell lymphoma: a retrospective study in 337 patients treated by chemotherapy with or without rituximab. Ann Oncol 22(7): 1601-1607.

Recher C, Coiffier B, Haioun C, Molina TJ, Ferme C, Casasnovas O, Thieblemont C, Bosly A, Laurent G, Morschhauser F, Ghesquieres H, Jardin F, Bologna S, Fruchart C, Corront B, Gabarre J, Bonnet C, Janvier M, Canioni D, Jais JP, Salles G, Tilly H. Groupe d'Etude des Lymphomes de 1A (2011) Intensified chemotherapy with ACVBP plus rituximab versus standard $\mathrm{CHOP}$ plus rituximab for the treatment of diffuse large B-cell lymphoma (LNH03-2B): an open-label randomised phase 3 trial. Lancet 378(9806): 1858-1867.

Ryan GF, Roos DR, Seymour JF (2006) Primary non-Hodgkin's lymphoma of the breast: retrospective analysis of prognosis and patterns of failure in two Australian centers. Clin Lymphoma Myeloma 6(4): 337-341.

Schmitz N, Zeynalova S, Glass B, Kaiser U, Cavallin-Stahl E, Wolf M, Haenel M, Loeffler M, Truemper L, Pfreundschuh M (2012) CNS disease in younger patients with aggressive B-cell lymphoma: an analysis of patients treated on the Mabthera International Trial and trials of the German High-Grade Non-Hodgkin Lymphoma Study Group. Ann Oncol 23(5): 1267-1273.

Schmitz N, Zeynalova S, Nickelsen M, Ziepert M, Pfreundschuh M, Glass B, Loeffler M (2013) A new prognostic model to assess the risk of CNS disease in patients with aggressive B-cell lymphoma. Hematol Oncol 31(S1): 96-150.

Shimazu Y, Notohara K, Ueda Y (2009) Diffuse large B-cell lymphoma with central nervous system relapse: prognosis and risk factors according to retrospective analysis from a single-center experience. Int J Hematol 89(5): $577-583$.

Siegal T, Goldschmidt N (2012) CNS prophylaxis in diffuse large B-cell lymphoma: if, when, how and for whom? Blood Rev 26(3): 97-106.

Swerdlow SH, Campo E, Harris NL, Jaffe ES, Pileri SA, Stein H, Thiele J, Vardiman JW (2008) WHO Classification of Tumors of the Hematopoeitic and Lymphoid Tissues. IARC: Lyon.

Tai WM, Chung J, Tang PL, Koo YX, Hou X, Tay KW, Quek R, Tao M, Lim ST (2011) Central nervous system (CNS) relapse in diffuse large B cell lymphoma (DLBCL): pre- and post-rituximab. Ann Hematol 90(7): 809-818.

Tilly H, Lepage E, Coiffier B, Blanc M, Herbrecht R, Bosly A, Attal M, Fillet G, Guettier C, Molina TJ, Gisselbrecht C, Reyes F. Groupe d'Etude des Lymphomes de lA (2003a) Intensive conventional chemotherapy (ACVBP regimen) compared with standard CHOP for poor-prognosis aggressive non-Hodgkin lymphoma. Blood 102(13): 4284-4289.

Tilly H, Lepage E, Coiffier B, Blanc M, Herbrecht R, Bosly A, Attal M, Fillet G, Guettier C, Molina TJ, Gisselbrecht C, Reyes F. l'Adulte ftGdEdLd (2003b) Intensive conventional chemotherapy (ACVBP regimen) compared with

\section{APPENDIX}

\section{Chemotherapy protocols}

(R) CHOP (rituximab $375 \mathrm{mg} \mathrm{m}^{-2}$ D1) Cyclophosphamide $750 \mathrm{mg} \mathrm{m}^{-2} \mathrm{D} 1$; doxorubicin $50 \mathrm{mg} \mathrm{m}^{-2} \mathrm{D} 1$; vincristine $1.4 \mathrm{mg} \mathrm{m}^{-2}$ IV capped at $2 \mathrm{mg} \mathrm{D1}$; prednisolone $100 \mathrm{mg}$ D1-5 p.o. (R) Hyper CVAD A cycle (rituximab $375 \mathrm{mg} \mathrm{m}^{-2}$ D1) Cyclophosphamide $300 \mathrm{mg} \mathrm{m}^{-2}$ IV twice daily D1-3; methotrexate $12 \mathrm{mg}$ IT D1; doxorubicin $50 \mathrm{mg} \mathrm{m}^{-2}$ IV D3; vincristine $1 \mathrm{mg} \mathrm{m}^{-2}$ (max $2 \mathrm{mg}$ ) IV D3, 11; dexamethasone $40 \mathrm{mg}$ p.o. D1-4 and 11-14.

$B$ cycle (rituximab $375 \mathrm{mg} \mathrm{m}^{-2} \mathrm{D} 1$ ) Methotrexate $1 \mathrm{~g} \mathrm{~m}^{-2}$ IVI (over 24h) D1; cytarabine $3 \mathrm{~g} \mathrm{~m}^{-2}$ IVI twice daily D2, 3; methotrexate $12 \mathrm{mg}$ IT D1.

CODOXM (rituximab $375 \mathrm{mg} \mathrm{m}^{-2} \mathrm{D} 1$ ) Cyclophosphamide $800 \mathrm{mg} \mathrm{m}^{-2}$ IV D1; cyclophosphamide $200 \mathrm{mg} \mathrm{m}^{-2}$ IV D2-5; vincristine $1.5 \mathrm{mg} \mathrm{m}^{-2}(\max 2 \mathrm{mg})$ IV D1, 8; doxorubicin $40 \mathrm{mg} \mathrm{m}^{-2}$ IV D1; cytarabine $70 \mathrm{mg}$ IT D1, 3; methotrexate $1 \mathrm{~g} \mathrm{~m}^{-2}$ IVI (over $24 \mathrm{~h}$ ). IVAC Ifosfamide $1.5 \mathrm{~g} \mathrm{~m}^{-2}$ IV D1-5; standard CHOP for poor-prognosis aggressive non-Hodgkin lymphoma. Blood 102(13): 4284-4289.

Tomita N, Yokoyama M, Yamamoto W, Watanabe R, Shimazu Y, Masaki Y, Tsunoda S, Hashimoto C, Murayama K, Yano T, Okamoto R, Kikuchi A, Tamura K, Sato K, Sunami K, Shibayama H, Takimoto R, Ohshima R, Hatta Y, Moriuchi Y, Kinoshita T, Yamamoto M, Numata A, Ishigatsubo Y, Takeuchi K (2012) Central nervous system event in patients with diffuse large B-cell lymphoma in the rituximab era. Cancer Sci 103(2): 245-251.

van Besien K, Ha CS, Murphy S, McLaughlin P, Rodriguez A, Amin K, Forman A, Romaguera J, Hagemeister F, Younes A, Bachier C, Sarris A, Sobocinski KS, Cox JD, Cabanillas F (1998) Risk factors, treatment, and outcome of central nervous system recurrence in adults with intermediategrade and immunoblastic lymphoma. Blood 91(4): 1178-1184.

Villa D, Connors JM, Shenkier TN, Gascoyne RD, Sehn LH, Savage KJ (2010) Incidence and risk factors for central nervous system relapse in patients with diffuse large B-cell lymphoma: the impact of the addition of rituximab to CHOP chemotherapy. Ann Oncol 21(5): 1046-1052.

Yamamoto W, Tomita N, Watanabe R, Hattori Y, Nakajima Y, Hyo R, Hashimoto C, Motomura S, Ishigatsubo Y (2010) Central nervous system involvement in diffuse large B-cell lymphoma. Eur J Haematol 85(1): 6-10.

Zhang J, Chen B, Xu X (2014) Impact of rituximab on incidence of and risk factors for central nervous system relapse in patients with diffuse large B-cell lymphoma: a systematic review and meta-analysis. Leuk Lymphoma 55(3): 509-514.

Zinzani PL, Magagnoli M, Frezza G, Prologo G, Gherlinzoni F, Bendandi M, Albertini P, Babini L, D’Alessandro R, Tura S (1999) Isolated central nervous system relapse in aggressive non-Hodgkin's lymphoma: the Bologna experience. Leuk Lymphoma 32(5-6): 571-576.

Zucca E, Conconi A, Mughal TI, Sarris AH, Seymour JF, Vitolo U, Klasa R, Ozsahin M, Mead GM, Gianni MA, Cortelazzo S, Ferreri AJ, Ambrosetti A, Martelli M, Thieblemont C, Moreno HG, Pinotti G, Martinelli G, Mozzana R, Grisanti S, Provencio M, Balzarotti M, Laveder F, Oltean G, Callea V, Roy P, Cavalli F, Gospodarowicz MK. International Extranodal Lymphoma Study G (2003) Patterns of outcome and prognostic factors in primary large-cell lymphoma of the testis in a survey by the International Extranodal Lymphoma Study Group. J Clin Oncol 21(1): 20-27.

This work is published under the standard license to publish agreement. After 12 months the work will become freely available and the license terms will switch to a Creative Commons AttributionNonCommercial-Share Alike 3.0 Unported License.

etoposide $60 \mathrm{mg} \mathrm{m}^{-2}$ IV D1-5; cytarabine $2 \mathrm{~g} \mathrm{~m}^{-2}$ IV twice daily D1-2; methotrexate $12 \mathrm{mg}$ IT D5.

(R)-MACOPB (rituximab $375 \mathrm{mg} \mathrm{m}^{-2}$ D1) Methotrexate $400 \mathrm{mg} \mathrm{m}^{-2}$ IV weeks 2, 6, 10; doxorubicin $50 \mathrm{mg} \mathrm{m}^{-2}$ IV weeks 1, 3, 5, 7, 9, 11; cyclophosphamide $350 \mathrm{mg} \mathrm{m}^{-2}$ IV weeks 1, 3, 5, 7, 9, 11; vincristine $1.4 \mathrm{mg} \mathrm{m}^{-2}$ (capped at $2 \mathrm{mg}$ ) IV weeks $2,4,6,8$, 10,12 ; prednisolone $75 \mathrm{mg}$ daily bleomicin $10 \mathrm{mg} \mathrm{m}^{-2}$ IV weeks 4 , 8,12 .

\section{ACVBP}

Four induction courses (Q21 days)

Doxorubicin $75 \mathrm{mg} \mathrm{m}^{-2}$ IV D1; cyclophosphamide $1200 \mathrm{mg} \mathrm{m}^{-2}$ intravenously D1; vindesine $2 \mathrm{mg} \mathrm{m}^{-2}$ on D1, 5; bleomycin $10 \mathrm{mg} \mathrm{D1}, 5$; prednisone $60 \mathrm{mg} \mathrm{m}^{-2}$ orally D1-5; methotrexate $15 \mathrm{mg}$ IT D2.

\section{Consolidation therapy (Q14 days)}

Methotrexate $3 \mathrm{~g} \mathrm{~m}^{-2}$ IV plus leucovorin rescue $\times 2$; etoposide $300 \mathrm{mg} \mathrm{m}^{-2} \mathrm{IV} \times 4$; ifosfamide $1500 \mathrm{mg} \mathrm{m}^{-2} \mathrm{IV} \times 4$; cytosinearabinoside $100 \mathrm{mg} \mathrm{m}^{-2}$ subcutaneously D1-4. 